\title{
Twin congenital epulis in the alveolar ridge of the maxilla and mandible in a newborn: a rare and interesting case
}

\author{
Deepak Sharma, ${ }^{1}$ Srinivas Murki, ${ }^{1}$ Tejo Pratap, ${ }^{1}$ Vallamsetty Leelakumar ${ }^{2}$
}

'Department of Neonatology, Fernandez Hospital,

Hyderabad, Andhra Pradesh, India

${ }^{2}$ Department of Pediatric Surgery, Suraksha Children's Hospital, Tarnaka, Hyderabad, India

\section{Correspondence to} Dr Deepak Sharma, dr.deepak.rohtak@gmail.com

Accepted 14 August 2014

\section{DESCRIPTION}

Case

A term female with birth weight of $2.9 \mathrm{~kg}$ was born to a primi mother through normal vaginal delivery. The infant had apgar scores of 8/9/9. At birth the infant was diagnosed with two masses originating from the left maxilla and mandible. The upper maxillary mass was pedunculated and $2 \times 2 \times 1.5 \mathrm{~cm}$ in size and the mandibular mass was $1.5 \times 1.5 \times 1 \mathrm{~cm}$ in size (figures 1-3). The infant was evaluated with head ultrasound, whole body X-ray and echocardiography for other malformations; all reports were normal. The infant was diagnosed as a case of congenital epulis and was operated on. Both the masses were removed and the postoperative course was uneventful; the infant was discharged. The histopathology report confirmed the diagnosis of epulis.

\section{Discussion}

Congenital epulis is also known as Neumann's tumour, granular cell tumour or congenital gingival granular cell tumour. ${ }^{1}$ The incidence of congenital epulis has been reported to be about $0.0006 \%$. The size of the lesion can vary from a few $\mathrm{mm}$ to $8 \mathrm{~cm} .^{2}$ This tumour is more common in women, with female-to-male ratio being $8: 1 .^{3}$ This tumour arises from the mucosa of the gingiva, usually from the anterior part of the maxillary alveolar ridge. On examination, infants with congenital epulis clinically present with a mass protruding from the mouth, which may produce difficulty in feeding or breathing if it is large. ${ }^{4}$ These tumours are uniformly benign in nature.

Differential diagnosis includes 5

- Hemangioma

- Lymphangioma

- Fibroma

- Granuloma

- Rhabdomyosarcoma

- Osteogenic sarcoma

- Chondrogenic sarcoma

- Schwannoma

- Heterotopic gastrointestinal cyst
To cite: Sharma D, Murki $S$, Pratap T, et al. BMJ Case Rep Published online: [please include Day Month Year] doi:10.1136/bcr-2014206490

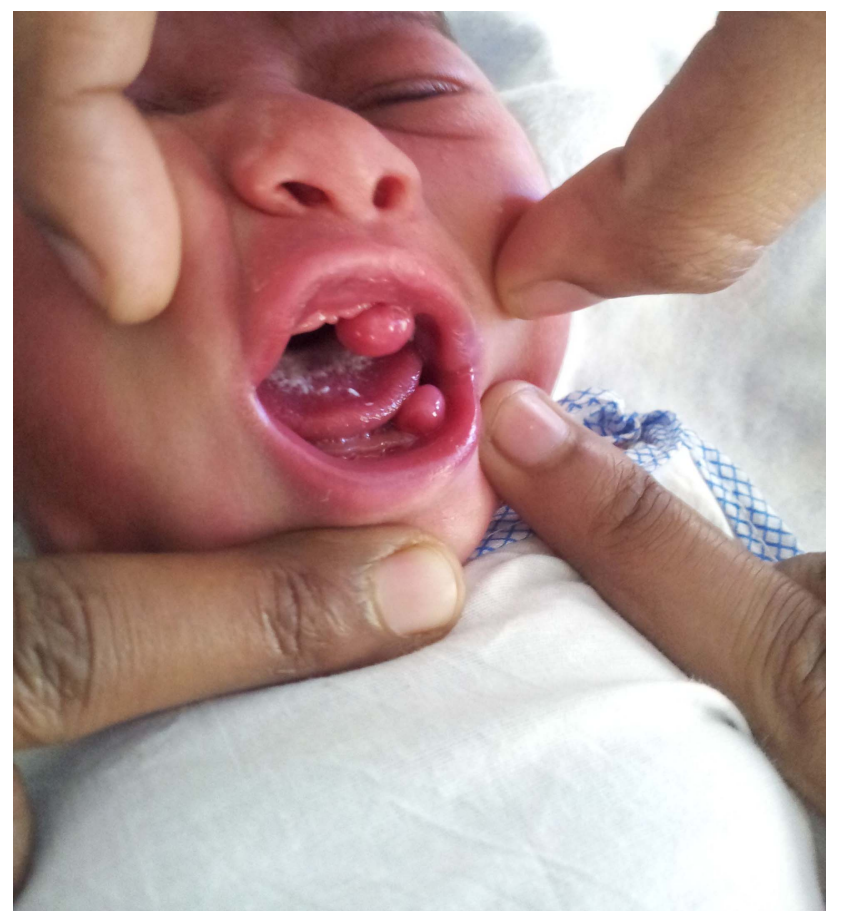

Figure 1 Two large pedunculated masses on the maxillary and mandibular alveolar ridges in a neonate female. Maxillary mass $2 \times 2 \times 1.5 \mathrm{~cm}$ in size and mandibular mass $1.5 \times 1.5 \times 1 \mathrm{~cm}$ in size. 


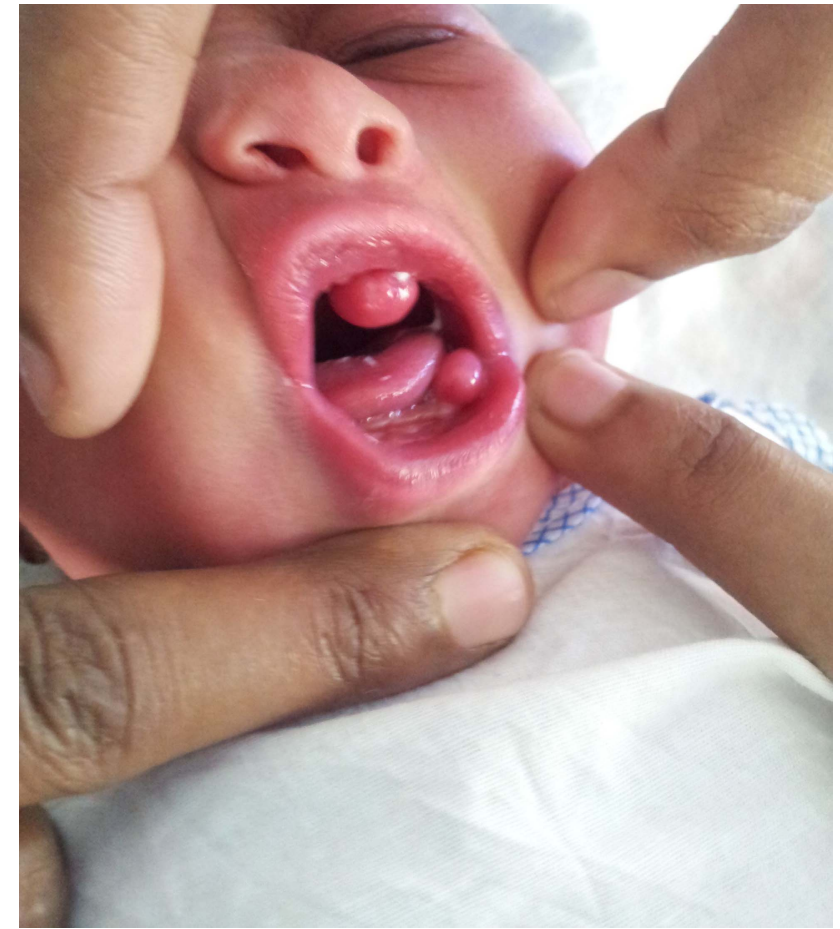

Figure 2 Two large pedunculated masses on the maxillary and mandibular alveolar ridges in a neonate female. Maxillary mass $2 \times 2 \times 1.5 \mathrm{~cm}$ in size and mandibular mass $1.5 \times 1.5 \times 1 \mathrm{~cm}$ in size.

Histology shows polygonal cells with pink, PAS-positive granular cytoplasm and regular, round, dark basophilic-staining nuclei. ${ }^{6}$ The recommended treatment is prompt surgical resection. These tumours have very good prognosis.?

\section{Key messages}

- Twin congenital epulis are very rare tumours seen at birth.

- Prompt surgical excisison is the treatment of choice.

- These tumours should be confirmed with histopathology as other conditions can also present in similar fashion.

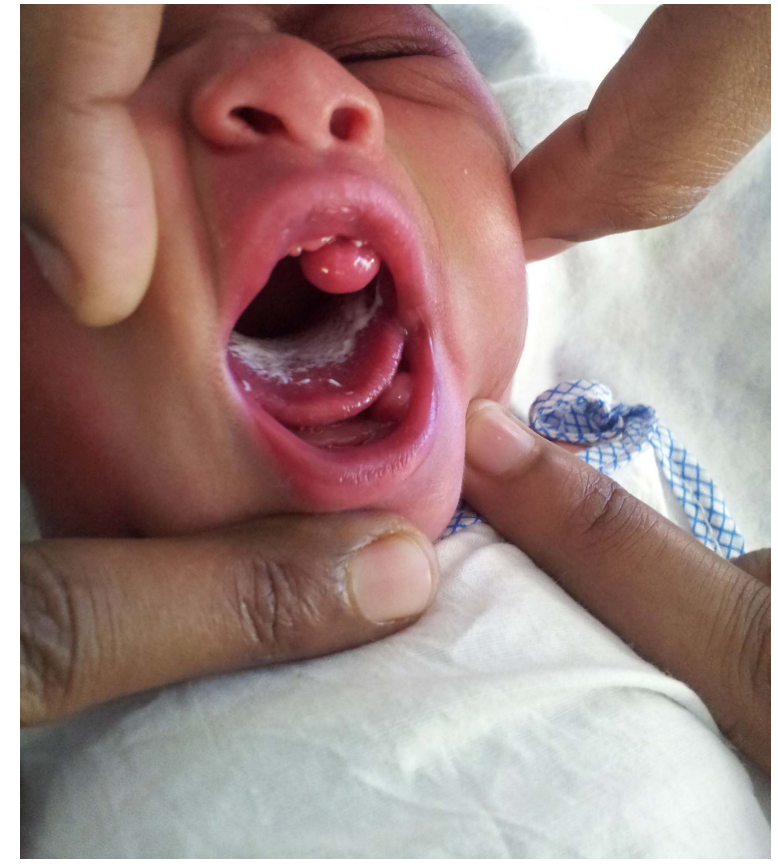

Figure 3 Two large pedunculated masses on the maxillary and mandibular alveolar ridges in a neonate female. Maxillary mass $2 \times 2 \times 1.5 \mathrm{~cm}$ in size and mandibular mass $1.5 \times 1.5 \times 1 \mathrm{~cm}$ in size.

Competing interests None.

Patient consent Obtained.

Provenance and peer review Not commissioned; externally peer reviewed.

\section{REFERENCES}

1 Neumann E. Elin fall von congaliter epulis. Arch Helik 1871;12:189.

2 Zuker RM, Buenecha R. Congenital epulis: review of the literature and case report. J Oral Maxillofac Surg 1993;51:1040-3.

3 Mueller DT, Callanan VP. Congenital malformations of the oral cavity. Otolaryngol Clin North Am 2007;40:141-60, vii.

4 Merrett SJ, Crawford PJ. Congenital epulis of the newborn: a case report. Int J Paedi Dent 2003;13:127-9.

5 Lapid O, Shaco-Levy R, Krieger Y, et al. Congenital epulis. Pediatrics 2001;107:E22.

6 Lack EE, Worsham GF, Callihan MD, et al. Gingival granular cell tumors of the newborn (congenital" epulis"): a clinical and pathologic study of 21 patients. Am J Surg Pathol 1981;5:37.

7 Kumar Dutta H. Jaw and gum tumours in children. Pediatr Surg Int 2009;25: 781-4. 